\title{
Obtenção de protoplastos do fungo filamentoso Aspergillus ochraceus
}

\author{
Production of protoplasts from the filamentous fungus Aspergillus ochraceus
}

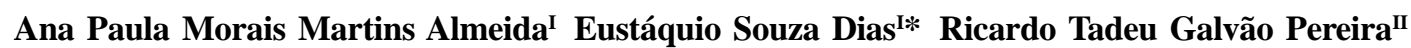 \\ Rômulo César Clemente Toledo ${ }^{I}$ Ludwig Heinrich Pfenning ${ }^{\mathrm{II}}$
}

\begin{abstract}
A obtenção de protoplastos é uma ferramenta importante para a transformação genética de fungos. Neste trabalho foi estudada a influência de fatores como idade micelial, tipo e concentração de enzimas e estabilizadores osmóticos na produção de protoplastos de Aspergillus ochraceus. Os melhores resultados de produção de protoplastos foram obtidos utilizando-se $\mathrm{NH}_{4} \mathrm{Cl}$ 0,8mol $\mathrm{L}^{-1}$ como estabilizador osmótico, micélio com $24 \mathrm{~h}$ de crescimento e a combinação de Lysing Enzymes e Meicelase ambas, a $20 \mathrm{mg} \mathrm{mL}^{-1}$. Entretanto, bons resultados foram também obtidos com a utilização apenas de Lysing Enzymes.
\end{abstract}

Palavras-chave: Aspergillus ochraceus, protoplastos e estabilizador osmótico.

\section{ABSTRACT}

Production of protoplasts is an important tool for genetic transformation of fungi. A protocol for protoplasts production in Aspergillus ochraceus was developed, evaluating culture aging of mycelium, different commercial enzymes and osmotic stabilizers. The best results were obtained with $\mathrm{NH}_{4} \mathrm{Cl}$ $0.8 \mathrm{~mol} \mathrm{~L}^{-1}$ as osmotic stabilizer, mycelial age of 24 hours and Lysing Enzymes (20mg mL $\mathrm{mL}^{-1}$ ) plus Meicelase (20mg $\mathrm{mL}^{-1}$ ) as lytic enzymes. Good results were also obtained with Lysing Enzymes alone.

Key words: Aspergillus ochraceus, protoplasts and osmotic stabilizer.

Uma das mais importantes micotoxinas encontradas em grãos de café é a ocratoxina A, produzida por vários fungos contaminantes, entre eles, Aspergillus ochraceus (BATISTA, 2003; SUÁREZQUIROZA et al., 2004). O processo de infecção da planta por A. ochraceus ainda não é conhecido, acreditandose que a entrada do fungo na planta ocorra pela flor. A marcação do fungo via transformação genética por meio de um eficiente sistema de expressão, como o GUS, pode ser uma importante estratégia para permitir o rastreamento do fungo na planta (FREEMAN et al., 1999) com o objetivo de se desenvolver métodos de controle. Entretanto, a transformação genética requer a utilização de procedimentos que tornem as células receptoras permeáveis à entrada do DNA. Entre vários tipos de procedimentos, destacam-se, para os fungos filamentosos, o tratamento de esporos com cátions divalentes (DHAWALE et al., 1984) e a obtenção de protoplastos (PEBERDY, 1976), os quais consistem em células destituídas de parede celular. Vários fatores influenciam a obtenção de protoplastos, entre eles, a preparação enzimática, o estabilizador osmótico, a idade micelial e o microrganismo a ser utilizado (PEBERDY, 1976). Este último requer a padronização de um protocolo de obtenção de protoplastos para cada espécie de microrganismo individualmente.

O presente trabalho teve como objetivo padronizar uma metodologia de obtenção de protoplastos de A. ochraceus isolado CML0560, pertencente à coleção micológica do Departamento de Fitopatologia da Universidade Federal de Lavras (UFLA).

\footnotetext{
IDepartamento de Biologia, Universidade Federal de Lavras (UFLA), CP 3037, 37200-000, Lavras, MG, Brasil. E-mail: esdias@ufla.br. *Autor para correspondência.

IIDepartamento de Fitopatologia, UFLA, Lavras, MG, Brasil.
} 
Os seguintes fatores foram avaliados: estabilizadores osmóticos (tipo e concentração), enzimas (tipo e concentração) e idade micelial. $\mathrm{O}$ pH dos estabilizadores osmóticos utilizados na preparação enzimática foi de 5,5. Além da preparação enzimática Lysing Enzymes de Trichoderma harzianum (Sigma), foram testadas também Glucanex (Sigma) e Meicelase (Karlan), usadas isoladamente ou em conjunto, em diferentes concentrações (10, 20 e 30 $\mathrm{mg} \mathrm{mL}^{-1}$ ).

Esporos de A. ochraceus foram inoculados em tubos contendo meio MEA inclinado ( $2 \%$ de glicose anidra, $2 \%$ de extrato de malte, $0,1 \%$ de peptona bacteriológica e 1,5\% de ágar). Após o crescimento micelial e a esporulação, foram adicionados $5 \mathrm{~mL}$ de solução salina 0,85\% para ressuspensão dos esporos, cuja concentração foi estimada por contagem em câmara de Neubauer. Para a produção de micélio, foi utilizada uma concentração final de $10^{6}$ esporos $\mathrm{mL}^{-1}$ e $30 \mathrm{~mL}$ de MEA líquido. Para os experimentos acerca dos estabilizadores osmóticos, concentração e tipo de enzima, os frascos foram incubados a $28^{\circ} \mathrm{C}$ com agitação de $100 \mathrm{rpm}$ durante $24 \mathrm{~h}$. Nos experimentos sobre idade micelial, os frascos inoculados foram mantidos sob agitação de $100 \mathrm{rpm}$ a $28^{\circ} \mathrm{C}$ por 20 e $24 \mathrm{~h}$.

Após o crescimento, o micélio foi filtrado a vácuo e lavado com 5mL de estabilizador osmótico, utilizando-se em média 100mg de micélio por mL de solução enzimática pH 5,5 para cada tratamento. Após o preparo da solução enzimática, o micélio foi acrescentado e o frasco foi incubado a $28^{\circ} \mathrm{C}$ sob agitação de 75rpm. A liberação de protoplastos foi avaliada por contagem em câmara de Neubauer a partir de alíquotas retiradas em intervalos de duas horas. Em todos os experimentos foram utilizadas cinco repetições e, para cada repetição, foram feitas quatro contagens em câmara de Neubauer. Para o teste de médias, foi utilizado o Teste de Tukey ao nível de 5\% de probabilidade.

$\mathrm{Na}$ avaliação dos diferentes estabilizadores osmóticos, a maior produção de protoplastos foi obtida com $\mathrm{NH}_{4} \mathrm{Cl}$ 0,6mol L-1 (Figura 1). Diferentes concentrações de $\mathrm{NH}_{4} \mathrm{Cl}$ foram também avaliadas $(0,2$ a $1,2 \mathrm{~mol} \mathrm{~L}^{-1}$ ), verificando-se que o $\mathrm{NH}_{4} \mathrm{Cl} 0,8 \mathrm{~mol} \mathrm{~L}^{-1}$ apresentou a maior liberação de protoplastos $(3 \mathrm{x}$ $10^{7}$ protoplastos $\mathrm{mL}^{-1}$ ) após seis horas de incubação com 20mg mL-1 de Lysing Enzymes (dados não mostrados).

O micélio produzido com 24 horas apresentou a maior liberação de protoplastos (2,85 x $10^{7}$ protoplastos $\mathrm{mL}^{-1}$ ), após quatro horas de digestão, utilizando-se Lysing Enzymes (20 $\mathrm{mg} \mathrm{mL}^{-1}$ ) e $\mathrm{NH}_{4} \mathrm{Cl}$ $0,8 \mathrm{~mol} \mathrm{~L}^{-1}$ como estabilizador osmótico. Segundo DIAS et al. (1997), a liberação de protoplastos foi menor quando se utilizou micélio com mais de $24 \mathrm{~h}$ de crescimento de Penicillium expansum e $\boldsymbol{P}$. griseoroseum, o que poderia estar associado à deposição de outras substâncias à parede celular, dificultando a liberação dos protoplastos.

Nos experimentos com diferentes enzimas, os melhores resultados foram obtidos quando utilizouse Lysing Enzymes em associação com Meicelase ou Meicelase e Glucanex, os quais não diferiram estatiscamente entre si (Figura 2). Estes resultados mostram que houve um efeito positivo da combinação de Lysing Enzymes e Meicelase, enquanto que a adição de Glucanex não influenciou na liberação de protoplastos. Por outro lado, é importante observar

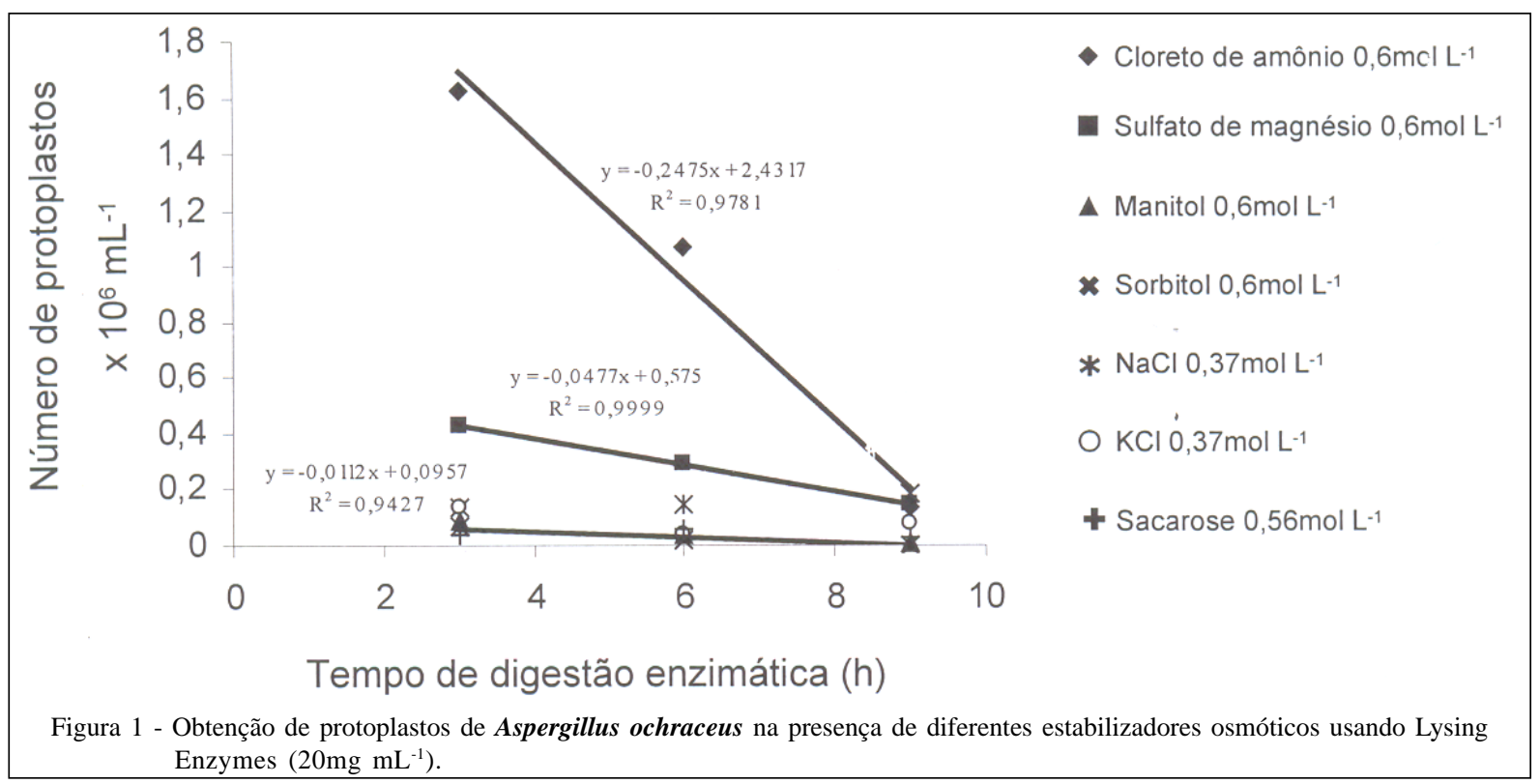

Ciência Rural, v.38, n.5, ago, 2008. 


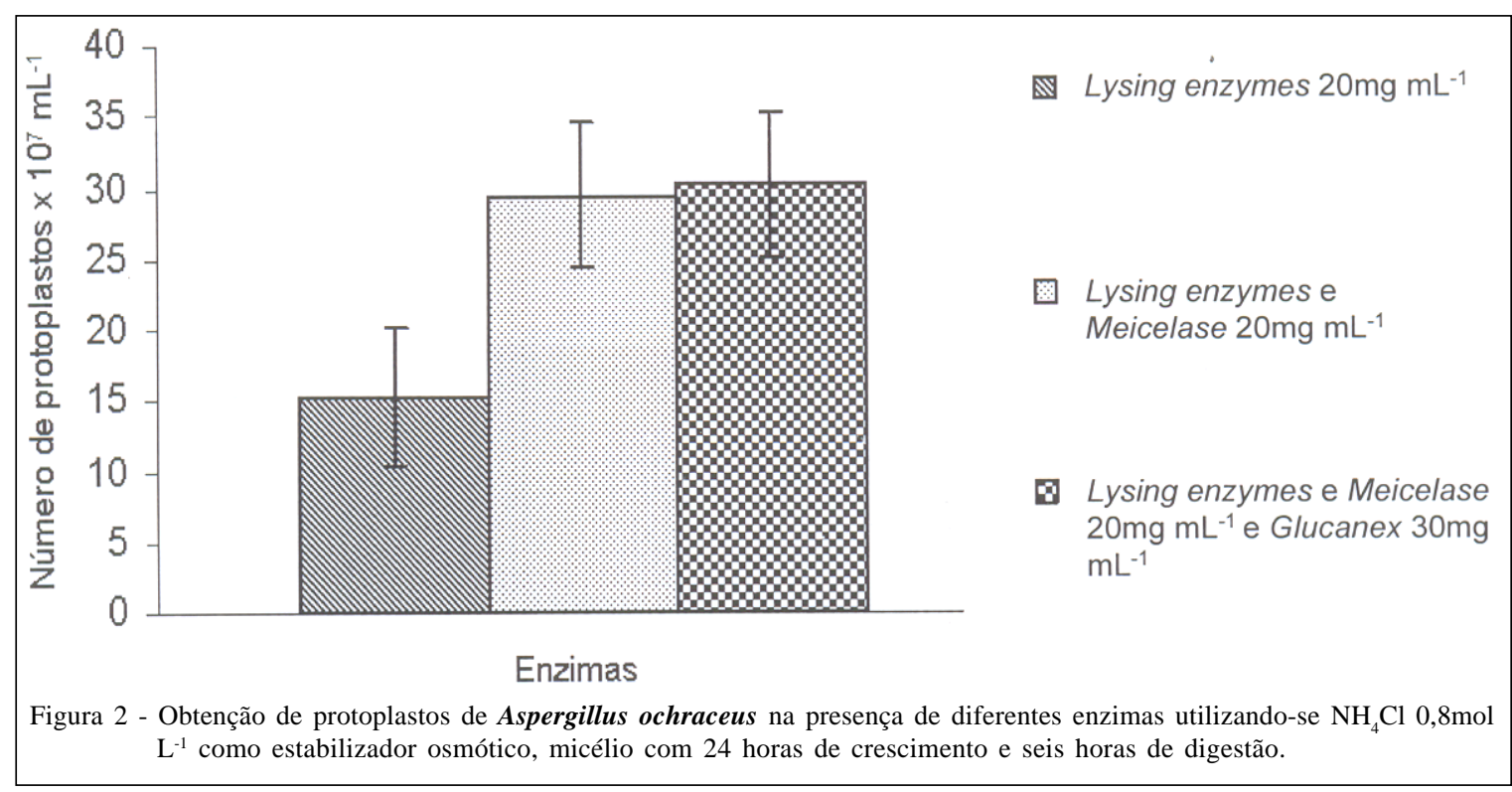

que, em diferentes experimentos para avaliação da concentração do estabilizador osmótico e da idade micelial, foram obtidos resultados similares, variando de 2,85 a 3,0 × $10^{8}$ protoplastos $\mathrm{mL}^{-1}$, utilizando-se apenas Lysing Enzymes (20 $\mathrm{mg} \mathrm{mL}^{-1}$ ). Como a liberação de protoplastos é extremamente sensível às condições fisiológicas do micélio, é comum se observar certa variação no número obtido entre diferentes experimentos, em função de fatores não controlados, como condição fisiológica dos esporos utilizados, oscilação da temperatura do ambiente de cultivo, etc. O mais importante, porém, é que o número de protoplastos em cada experimento mantenha-se acima de $10^{7} \mathrm{~mL}^{-1}$, uma vez que um elevado número de protoplastos é fundamental para a eficiência do processo de transformação. Os bons resultados obtidos quando se utilizou apenas Lysing Enzymes são importantes, uma vez que esta preparação enzimática é facilmente encontrada no mercado brasileiro. Portanto, para a obtenção de protoplastos de A. ochraceus, recomenda-se as seguintes condições: micélio com 24 h de crescimento, $\mathrm{NH}_{4} \mathrm{Cl}$

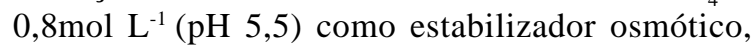

Lysing Enzymes e Meicelase, ou apenas Lysing Enzymes ambas a $20 \mathrm{mg} \mathrm{mL}^{-1}$.

\section{REFERÊNCIAS}

BATISTA, L.R. et al. Toxigenic fungi associated with processed (green) coffee beans (Coffea arabica L.). International Journal of Food Microbiology, v.85, p.293-300, 2003.

DHAWALE, S. et al. A new, rapid and efficient transformation procedure for Neurospora. Currents Genetics, v.8, p.7779, 1984.

DIAS, E.S. et al. Production and regeneration of Penicillium expansum e Penicillium griseoroseum protoplasts. Revista de Microbiologia, v.28, p.16-120, 1997.

FREEMAN, S. et al. Use of GUS transformants of Fusarium subglutinans for determining etiology of mango malformation disease. Phytopathology, v.89, n.6, p.456-461, 1999.

PEBERDY, J.F. et al. Factors affecting protoplast release in some filamentous fungi. Transactions of the British Mycological Society, v.67, n.1, p.23-26, 1976.

SUÁREZ-QUIROZA M.L. et al. Effect of chemical and environmental factors on Aspergillus ochraceus growth and toxigenesis in green coffee. Food Microbiology, v.21, p.629634, 2004. 